\title{
Model Based Adaptive Piecewise Linear Controller for Complicated Control Systems
}

\author{
Tain-Sou Tsay \\ Department of Aeronautical Engineering, National Formosa University, No. 64, Wen-Hua Road, Huwei, Yunlin, Taiwan \\ Correspondence should be addressed to Tain-Sou Tsay; tstsay@nfu.edu.tw
}

Received 1 July 2014; Revised 2 September 2014; Accepted 3 September 2014; Published 17 September 2014

Academic Editor: Baocang Ding

Copyright (C) 2014 Tain-Sou Tsay. This is an open access article distributed under the Creative Commons Attribution License, which permits unrestricted use, distribution, and reproduction in any medium, provided the original work is properly cited.

\begin{abstract}
A model based adaptive piecewise linear control scheme for industry processes with specifications on peak overshoots and rise times is proposed. It is a gain stabilized control technique. Large gain is used for large tracking error to get fast response. Small gain is used between large and small tracking error for good performance. Large gain is used again for small tracking error to cope with large disturbance. Parameters of the three-segment piecewise linear controller are found by an automatic regulating time series which is function of output characteristics of the plant and reference model. The time series will be converged to steady values after the time response of the considered system matching that of the reference model. The proposed control scheme is applied to four numerical examples which have been compensated by PID controllers. Parameters of PID controllers are found by optimization method. It gives an almost command independent response and gives significant improvements for response time and performance.
\end{abstract}

\section{Introduction}

Gain and phase stabilized are two conventional design methods for feedback control systems. They can be analyzed and designed in gain-phase plots to get wanted gain and phase margins or gain and phase crossover frequencies [1, $2]$. The gain crossover frequency is closely related to the system bandwidth (or response time). The phase margin is closely related to performance (or peak overshoot). In general, fast response time and good performance cannot be obtained simultaneously for some feedback control systems. For example, the altitude control system of the airframe needs large gain for fast response time and low gain for good performance. It is in conflict with another. Simple and effective way to solve this problem and provides better results than those of compensated by linear controllers are generally expected. This is the motivation of this paper.

Variable structure control is a switching control method for feedback control systems [3-7]. It gives good performance and robustness for coping with system uncertainty. But it suffers from chattering problem and state measurements. In this paper, a fast response system and a good performance system are selected for switching. An adaptive switching algorithm is used. There is no discontinuous connection between two systems. Therefore, there is no chattering problem. Gain scheduling has been used successfully to control nonlinear systems for many decades and in many different applications, such as autopilots and chemical processes [8-10]. It consisted of many linear controllers for operating points to cope with large parameter variations. This concept will be expanded for response time and performance. Operating points are replaced by fast response and good performance conditions and interpolation for gain evaluation is replaced by an adaptive switching point. It is determined by the filtered command tracking errors. Nonlinear controller's syntheses using inverse describing function for use with hard nonlinear system have developed for several researchers [11-13]. They are complicated but effective for nonlinear systems.

In this paper, a simple three-segment piecewise linear controller is proposed. It is symmetry and has two switching points. It is equivalent to two quasilinear gains; that is, there are two equivalent systems. One is the fast but bad performance system, and the other is the slow but good performance system. Switching points are used to select optimal 
gain. They are functions of the dynamic of tracking error. It is easy to analyse and design. Based on the information of the reference model, parameters of three-segment piecewise linear controller can be tuned in the online manner. An automatic regulating time series [14] is used for tuning the parameter. It can be retuned again if the system is needed. Furthermore, it gives an almost reference input independent response. It implies that the controlled system is similar to a linear system.

The proposed control scheme will be illustrated by a 2 nd order altitude control system and applied to four numerical examples those have been compensated by optimized PID controllers. Time responses show that the proposed method gives significant improvements on response time and performance than those compensated by PID controllers.

\section{The Model Based Control Scheme}

Figure 1 shows the proposed model based control scheme in which reference model represents the wanted system response, adaptive piecewise linear controller is a gain stabilized compensation, and autotuning process is used to find the switching point $\left(D_{1}\right)$ of the adaptive piecewise linear controller. The piecewise linear controller can get fast response and performance simultaneously. It is a threesegment piecewise linear controller. The switching point $\left(D_{1}\right)$ is dependent on the filtered dynamic of the tracking error $(E)$. Parameters $K_{1}, K_{2}, K_{n}$, and $T_{n}$ are found by the autotuning process for matching outputs of the reference model. Several identifying processes will be processed to find them. In general, the controlled system can be described by peak overshoot and rise time of step response. The concept of the proposed control scheme will be discussed by an illustrating example in next subsections.

2.1. The Adaptive Piecewise Linear Controller. Figure 1 shows the three-segment piecewise linear nonlinearity. Now, the problem is to find values of $K_{n}$ and $T_{n}$ for switching points $+D_{1}$ and $-D_{1}$ and gains $\left(K_{1}, K_{2}\right)$ for two selected systems; that is, one is the fast but bad performance system and the other is the slow but good performance system. Note that switching points $+D_{1}$ and $-D_{1}$ are not fixed and will be determined by the absolute value of the command tracking error.

Consider a 2 nd altitude control example described by

$$
G(s)=\frac{1}{s(s+2)} .
$$

The transfer function of the closed-loop system with loop gain $K$ is

$$
T(s)=\frac{K}{s^{2}+2 s+K} .
$$

Poles locations and natural frequency $\left(\omega_{n}\right)$ for two loop gains $\left(K_{1}, K_{2}\right)$ are

$$
\begin{gathered}
K_{1}=0.500, \text { poles : }-0.2929,-1.7071, \\
K_{2}=10.00, \quad \text { poles : }-1.0 \pm j 3.0, \quad \omega_{n}=3.1623 .
\end{gathered}
$$

They are overdamped and underdamped systems. Time responses of them are shown in Figure 2 for $K=K_{1}$ (smalldot-line) and $K=K_{2}$ (large-dot-line) in which $R$ represents the reference input and $C$ represents the output. The strategy for gain switching is (1) large gain $\left(K_{2}\right)$ for large tracking error to get fast response and (2) small gain $\left(K_{1}\right)$ for small tracking error $(E)$ to get good performance. It is a variable structure system and can be achieved by selecting a proper switching point $D_{1}$ of the piecewise linear controller. For example, the optimal switching point $D_{1}$ is selected as 0.525 for $R=1$ to get fast response and good performance. Large gain $\left(K_{2}\right)$ is used for $|E|>D_{1}$ and small gain $\left(K_{1}\right)$ is used for $|E| \leq D_{1}$. Step response is shown in Figure 2 (solid-line) also for $R=1$. It shows that the controlled system using adaptive gain can give fast response and good performance simultaneously.

However, it is not true that $R$ is equal to 5,10 , and 50 , respectively. Those step responses are shown in Figure 3. Naturally, another optimal switching point $D_{1}$ for $R=5,10$, and 50 can be selected for getting good performance. They are $2.625,5.250$, and 26.250 for $R=5,10$, and 50, respectively. They are true for step responses from zeros to 5,10 , and 50 only. Another possible way for the switching point can be dependent on the tracking error $(E)$. A possible switching rule for $D_{1}$ is found as $D_{1}=0.925|E|$ for good performance. Figure 4 shows time responses for $R=1,5,10$, and 50, respectively. It can be seen that the switching rule gives an input command $(R)$ independent of results. However, they are slower than those results shown in Figures 2 and 3.

One possible way to speed up the time response is to enlarge the large gain phase in the beginning. A low-pass filter $D(s)=K_{n} /\left(T_{n} s+1\right)$ is used for the absolute tracking error (E) to get $D_{1}$. Figure 5 shows that faster response than that shown in Figure 4 is got for $K_{n}=1.0465$ and $T_{n}=1 / \omega_{n}$. The switching point $D_{1}$ is shaped for speeding up the responses while keeping performance unchanged. Figure 5 shows that the rise time of the controlled system is quite close to that of the controlled system using $K=K_{2}$; that is, the rise time of the system is dependent on $K_{2}$. Note that the natural frequency $\left(\omega_{n}\right)$ for $K=K_{2}$ is used to find $T_{n}$ also. Therefore, it is needed to determine $K_{n}$ only.

Figure 6 shows time responses for $R=1,5,10$, and 50 , respectively. It shows that almost input independent responses are got. It implies that the controlled system is similar to the system controlled by linear controller. This is the major merit of the proposed method.

2.2. The Automatic Tuning Process. In general, one can use rise time and peak overshoot of step response to describe the characteristics of the controlled system. They will be used as specifications to find parameters of the adaptive piecewise linear controller, that is, $K_{1}, K_{2}, K_{n}$, and $T_{n}$.

2.2.1. Automatic Tuning Process for Matching Peak Point. Parameter $K_{n}=1.0465$ of the low-pass filter $D(s)=$ 


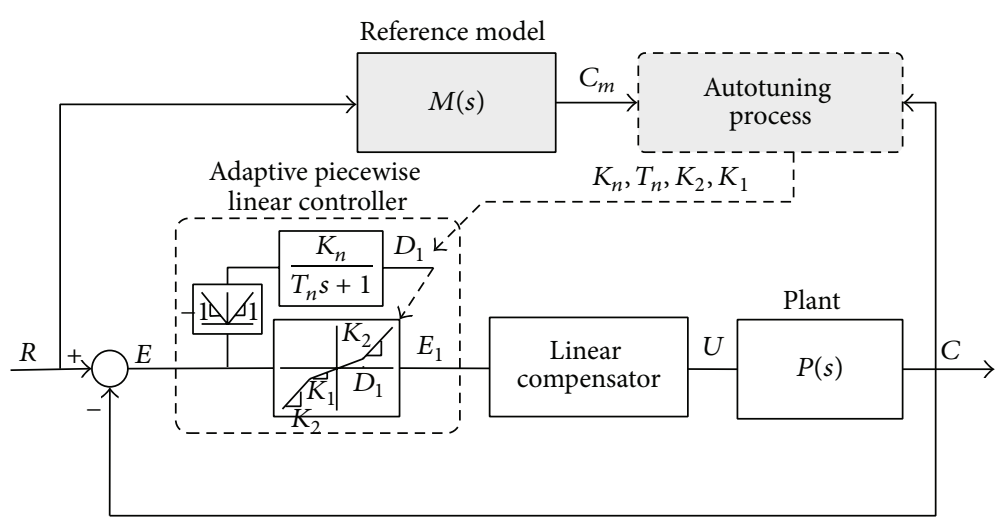

Figure 1: The proposed model based control scheme.

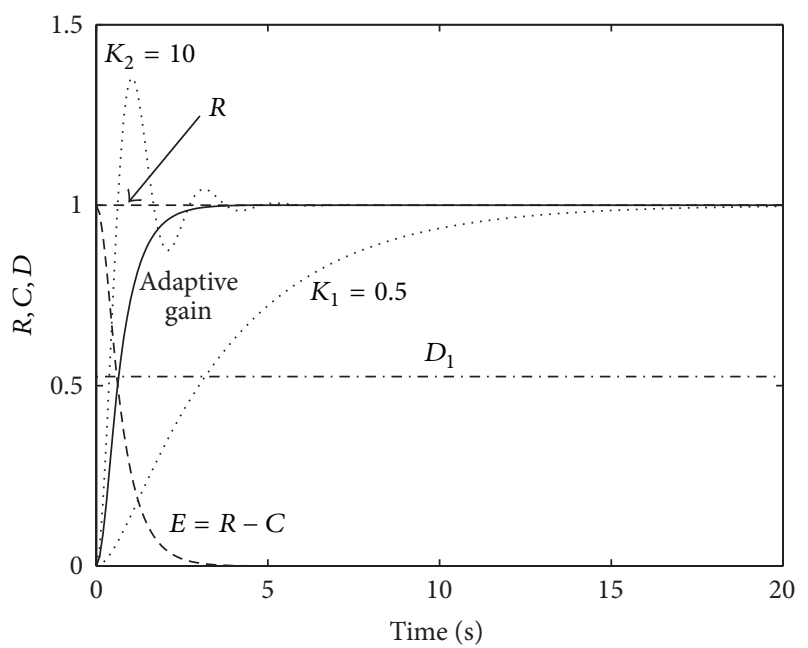

FIGURE 2: Time responses of the illustrating example for $K=0.5,10$ and adaptive gain.

$K_{n} /\left(T_{n} s+1\right)$ of the adaptive piecewise linear controller used in Section 2.1 was found by use of the following equations:

$$
\begin{gathered}
G_{n}(k T+T)=G_{n}(k T) \times\left\{\alpha\left[\frac{M p}{M p s}\right]^{j}+(1-\alpha)\right\} ; \\
0<\alpha<1 ; \\
K_{n}=G_{n}(k T),
\end{gathered}
$$

where $G_{n}(k T)$ is an automatic regulating time series [14]; $\alpha$ and $j$ are controlling parameters of the regulating property; $M p s$ is the specification of the peak value; $M p$ is the peak point found by using $K_{n}=G_{n}(k T)$; $T$ is simulation period of one step response; and $k$ is the $k$ th step responses. Equation (4) gives that $G_{n}(k T)$ will be converged to a steady-state value after $M p s$ being matched by $M p$.

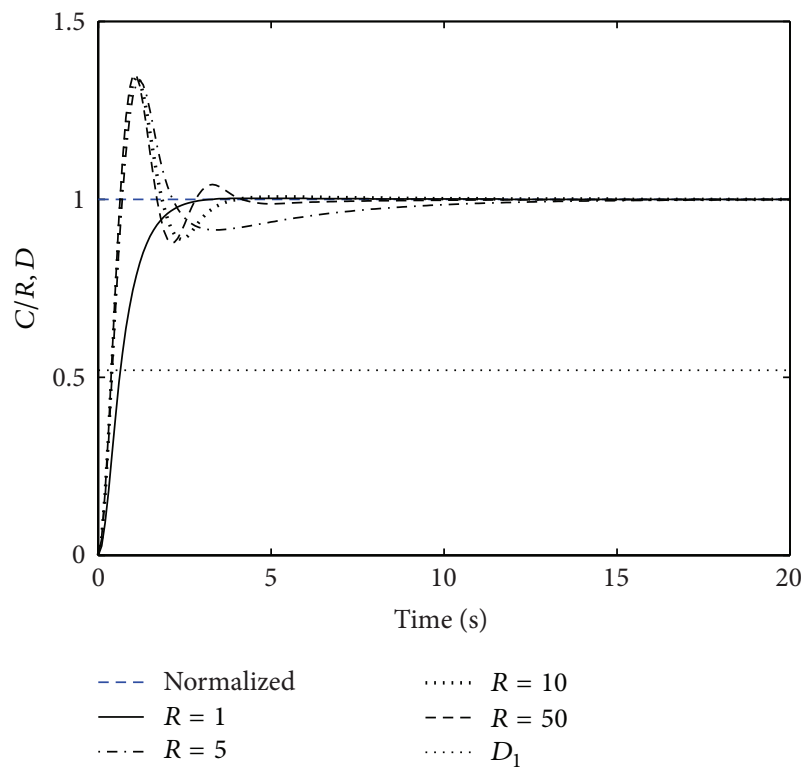

FIGURE 3: Time responses of the illustrating example for $R=1,5,10$, and 50 and $D_{1}=0.525$.

Figure 7 shows the online tuning process for $T=30 \mathrm{sec}$; $\alpha=0.9 ; M p s=1.003 ; j=3$. The values of $G_{n}(k T)$ in each tuning interval are

$$
\begin{array}{ccrl}
G_{n}(0) & =0.30, & G_{n}(T)=0.6004, \\
G_{n}(2 T) & =0.9580, & G_{n}(3 T)=1.0465, \\
G_{n}(0) & =0.50, & G_{n}(T)=0.8678, \\
G_{n}(2 T) & =1.0484, & G_{n}(3 T)=1.0465, \\
G_{n}(0) & =0.70, & G_{n}(T)=1.0122, \\
G_{n}(2 T) & =1.0453, & G_{n}(3 T)=1.0465,
\end{array}
$$

for three initial guesses $G_{n}(0)$. They show that $G_{n}(k T)$ are converged to 1.0465 quickly. Figure 7 shows also that the final system matches the peak specification $M p s$. 


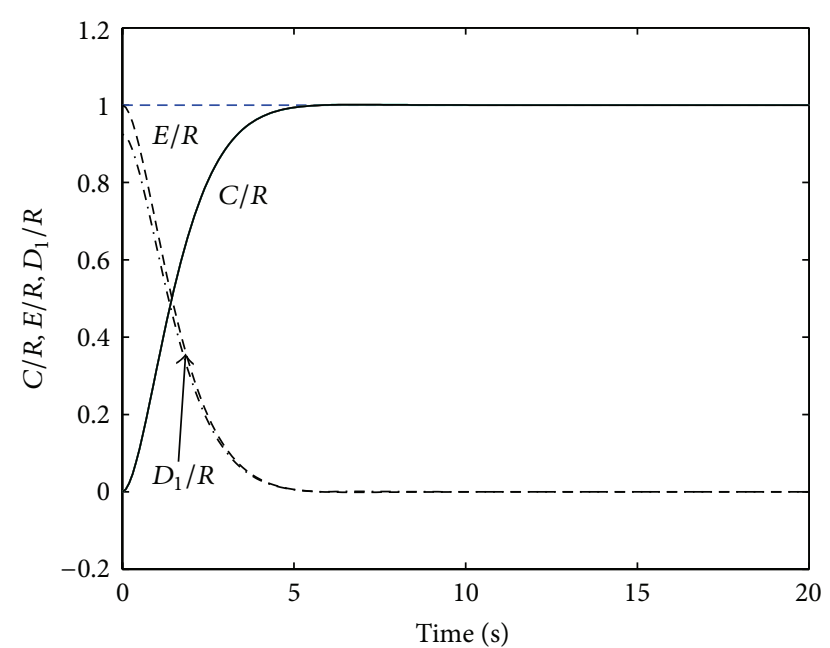

FIgURE 4: Time responses of the illustrating example for $R=1,5,10$, and 50 and $D_{1}=0.925|E|$.

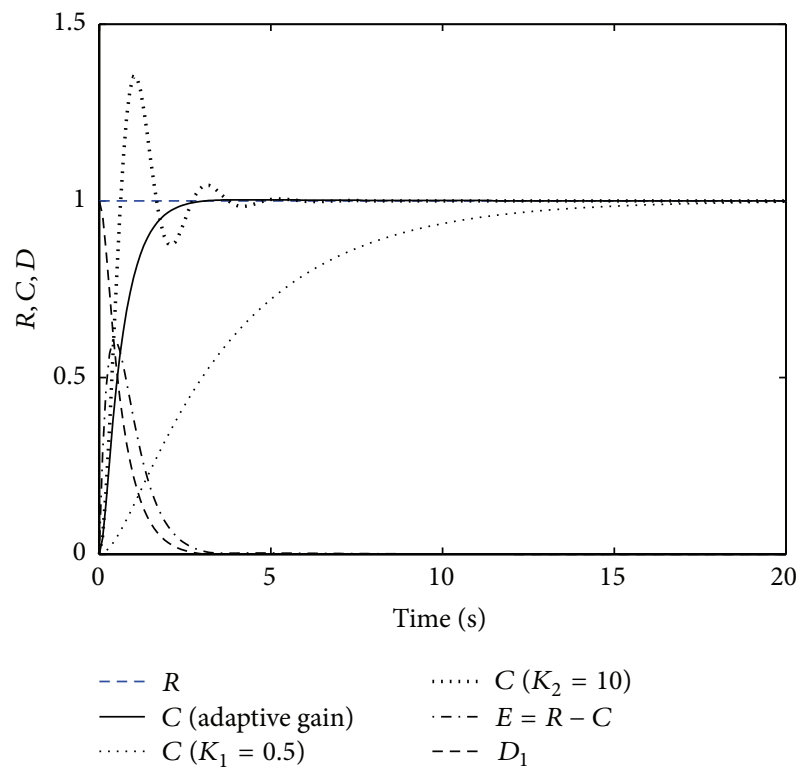

FIGURE 5: Time responses of the illustrating example for $R=1$ and $D(s)=K_{n} /\left(T_{n} s+1\right)$.

\subsubsection{Automatic Tuning Process for Matching Peak Point and} Rise Time. In the previous subsection, specification Mps is used to find parameter $K_{n}$. Another specification for rise time $T_{c}$ can be also used to tune high gain $K_{2}$ and $T_{n}$. Automatic tuning equations are described as follows:

$$
\begin{aligned}
& Q_{n}(k T+T)= Q_{n}(k T) \times\left\{\beta\left[\frac{T_{c}}{T_{c s}}\right]^{l}+(1-\beta)\right\} ; \\
& S_{C K 2}=Q_{n}(k T),
\end{aligned}
$$

where $\beta$ is regulating parameter and $K_{2}, K_{1}$, and $T_{n}$ will be replaced by $K_{2} S_{C K 2}, K_{1} / S_{C K 2}$, and $T_{n} / S_{C K 2}$, respectively. Figure 8 shows the online automatic tuning process for

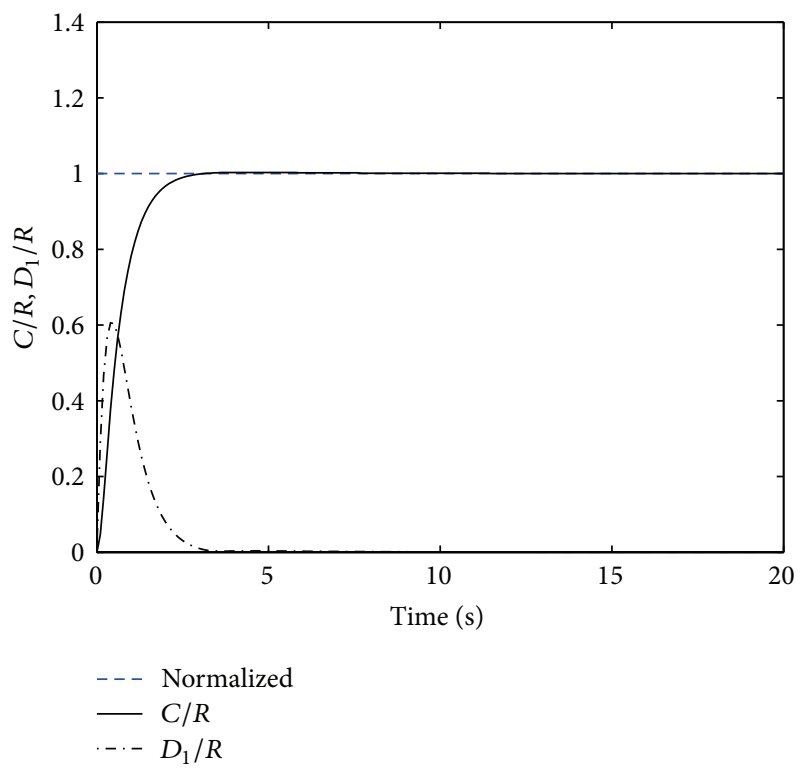

FIGURE 6: Time responses of the illustrating example for $R=1,5,10$, and 50 .

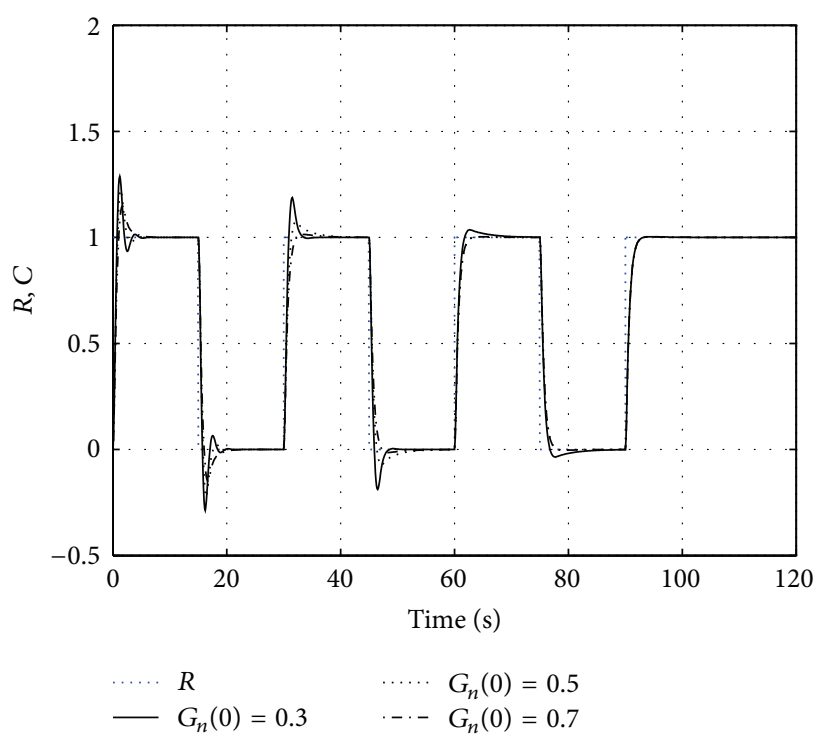

FIGURE 7: Online automatic tuning process of the illustrating example using different initial $G_{n}(0)$.

matching peak point and rise time specifications, simultaneously. Specifications used are $M p s=1.003$ and $T_{c s}=0.60 \mathrm{sec}$. Parameters used in (4) and (7) are $\alpha=0.6, \beta=0.5, j=5, T=$ $30 \mathrm{sec}, G_{n}(0)=0.7$, and $Q_{n}(0)=1.00$. Internal values of each tuning interval are given in Table 1 . Table 1 gives that system response is converged into wanted specification quickly. Note that system response shown in Figure 8 is faster than that shown in Figure 7. 


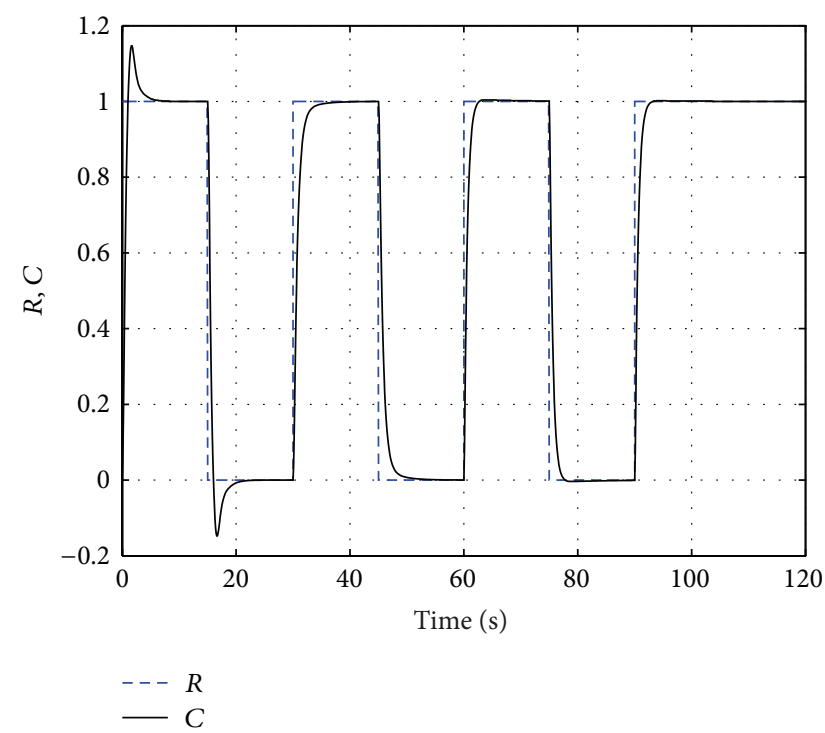

FIGURE 8: Online automatic tuning process of the illustrating example for matching peak point and rise time specification.

TABLE 1: Internal values of each tuning interval.

\begin{tabular}{lccccc}
\hline Time & 0 & $\mathrm{~T}$ & $2 \mathrm{~T}$ & $3 \mathrm{~T}$ & $4 \mathrm{~T}$ \\
\hline$G_{n}(\mathrm{kT})$ & 0.70 & 1.101 & 1.091 & 1.093 & 1.091 \\
$Q_{n}(\mathrm{kT})$ & 1.00 & 0.815 & 1.979 & 1.927 & 1.928 \\
$M p s$ & 1.147 & 1.000 & 1.004 & 1.003 & 1.003 \\
$T_{c}$ & 0.547 & 0.786 & 0.594 & 0.600 & 0.600 \\
\hline
\end{tabular}

Design procedures for the proposed method using the proposed adaptive piecewise linear controller can be deduced as follows.

Step 1. Select two loop gains for fast response and good performance, respectively. In general, high loop gain $(K=$ $\left.K_{2}\right)$ is for fast responses and low gain $\left(K=K_{1}\right)$ is for good performance. The rise time of the system with high gain meets the design specification. The peak overshoot of the system with low gain meets the design specification.

Step 2. Determine parameters of low-pass filter $D(s)=$ $K_{n} /\left(T_{n} s+1\right)$ to find the optimal switching point $D_{1}$. The natural frequency $\left(\omega_{n}\right)$ for the high gain system $\left(K=K_{2}\right)$ is used to find $T_{n}$. The natural frequency $\left(\omega_{n}\right)$ is closely related to the rise time. Equations (4)-(8) are used to find parameters $K_{1}, K_{2}, K_{n}$, and $T_{n}$ for given specifications $M p s$ and $T_{c s}$. Another method for finding parameter $K_{n}$ can be used by the optimization method using performance index formulated by integration of the absolute error (IAE) and integration of the square error (ISE) oronline parameterized method $[15,16]$.

The proposed control scheme will be applied to four numerical examples which have been compensated by optimized PID controllers.

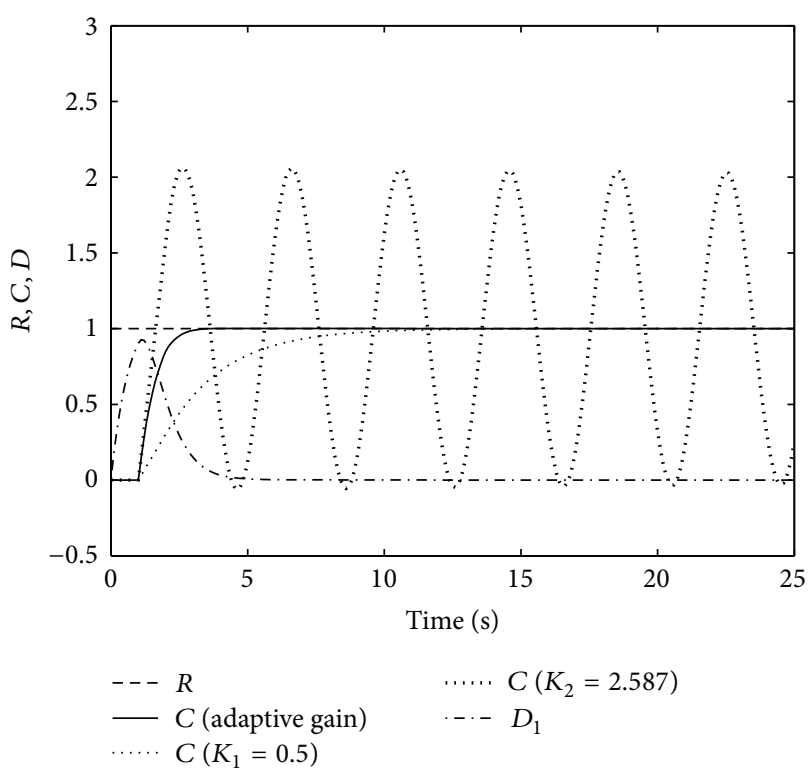

FIgURE 9: Step responses of Example 1 for constant gains $(K=0.5$ and 2.587) and adaptive gain with $D_{1}$.

\section{Numerical Examples}

Example 1. Consider a stable plant that has the transfer function [17]

$$
G(s)=\frac{e^{-s}}{(s+1)^{2}}
$$

It is a second order dynamic plus a pure time delay (SOPDT). In this example, parameters of the PID controller are

$$
K_{p}=1.1953, \quad K_{i}=0.5942, \quad K_{d}=0.7338 .
$$

It is designed by optimization method first and closed with it. And then low loop gain $K_{1}=0.50$ in cascade is selected and high loop gain $K_{2}=2.587$ in cascade is selected for the system which is just in the sustaining oscillating condition. Time responses using low gain $\left(K_{1}=0.50\right)$ and high gain $\left(K_{2}=2.587\right)$ are shown in Figure 9. The oscillation frequency is $\omega_{n}=1.5708 \mathrm{rad} / \mathrm{s}$. It shows an overdamped system and a zero-damped system. An optimal parameter $K_{n}$ for switching point $D_{1}$ will be selected to coordinate two systems for matching system specifications.

Now, apply the proposed control scheme to the system using

$$
K_{1}=0.5000, \quad K_{2}=2.587, \quad T_{n}=0.6366 .
$$

The $K_{n}$ is found by following online computing rule:

$$
\begin{gathered}
G_{n}(k T+T)=G_{n}(k T) \times\left\{0.9\left[\frac{M p c}{M p s}\right]^{2}+0.1\right\}, \\
K_{n}=G_{n}(k T)
\end{gathered}
$$


with $G_{n}(0)=0.5, T=25$ seconds, and $M p s=1.001$. The found $G_{n}(k T)$ are

$$
\begin{gathered}
G_{n}(0)=0.5, \quad G_{n}(T)=1.0794, \quad G_{n}(2 T)=1.1365, \\
G_{n}(3 T)=1.1385, \quad G_{n}(4 T)=1.1385, \ldots
\end{gathered}
$$

$G_{n}(k T)$ is converged to be 1.1385 within three period simulations. The online autotuning process is shown in Figure 10.

The time response is shown in Figure 9 also. It can be seen that the proposed method can give fast response and good performance simultaneously. It is the combination of overdamped and zero-damped systems with $D_{1}$. Zerodamped system is used for fast responses and overdamped system is used for good performance. Naturally, it is almost input command $(R)$ independent also.

Simulation results of the proposed method and four other methods are presented for comparisons. They are methods of Ziegler-Nichols $[18,19]$ for finding PI and PID compensators, Tan et al. [20, 21] for finding PID compensator, and Majhi [17] for finding PI compensator. Parameters of five found compensators are given as follows.

(1) Proposed method:

$$
\begin{aligned}
& K_{p}=1.1953, \quad K_{i}=0.5942, \quad K_{d}=0.7338, \\
& K_{1}=0.5000, \quad K_{2}=2.587, \quad K_{n}=1.1385, \\
& T_{n}=0.6366 .
\end{aligned}
$$

(2) $\mathrm{ZN}(\mathrm{PI}): K_{p}=1.240$ and $K_{i}=0.251$.

(3) ZN(PID): $K_{p}=1.6367, K_{i}=0.4187$, and $K_{d}=$ 0.5972 .

(4) Tan's(PID): $K_{p}=0.620, K_{i}=0.5636$, and $K_{d}=$ 0.1705.

(5) Majhi's(PI): $K_{p}=0.864$ and $K_{i}=0.3653$.

Time responses are shown in Figure 11. Integral of the square error (ISE) and integral of the absolute error (IAE) are given in Table 2. From Table 2 and Figure 11, one can see that the proposed method gives faster response and better performance than those of other methods presented.

Example 2. Consider the sixth-order plant [17]

$$
G(s)=\frac{1}{(s+1)^{6}} .
$$

Three parameters of the optimized PID controller are

$$
K_{p}=1.1800, \quad K_{i}=0.3380, \quad K_{d}=2.9181 .
$$

The performance index 50IAE + ISE is used for finding them. The dominate pole for high gain $K_{2}=1.500$ is $-0.0848 \pm$ $j 0.7898$. The natural frequency is $\omega_{n}=0.7943 \mathrm{rad} / \mathrm{s}$. It is an underdamped system. The low gain $K_{1}=0.05$ is selected. It is an overdamped system. Parameters for the proposed control scheme found are

$$
\begin{array}{cl}
K_{1}=0.0500, & K_{2}=1.500, \quad K_{n}=0.5064, \\
T_{n} & =1.259 .
\end{array}
$$

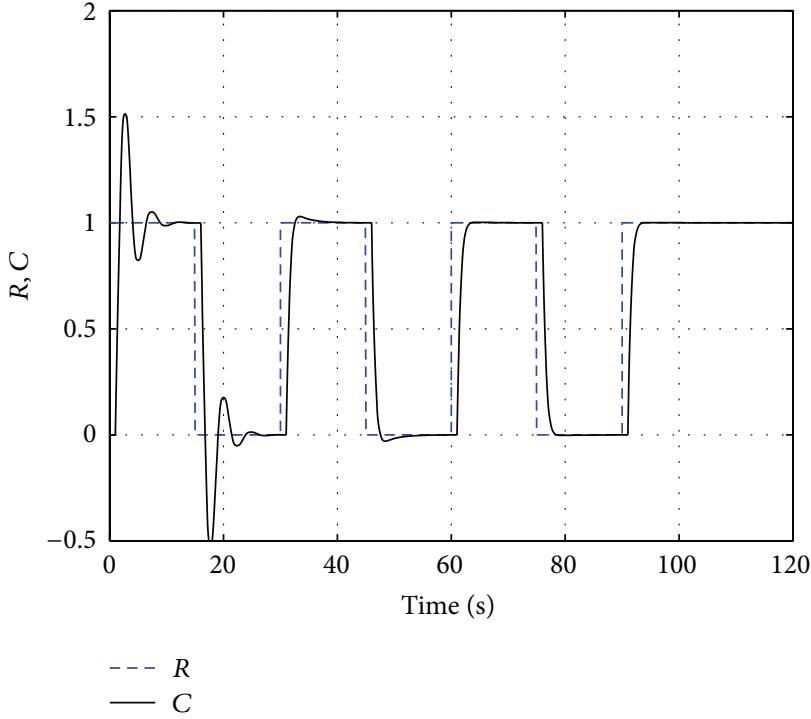

FIGURE 10: Online autotuning process of Example 1.

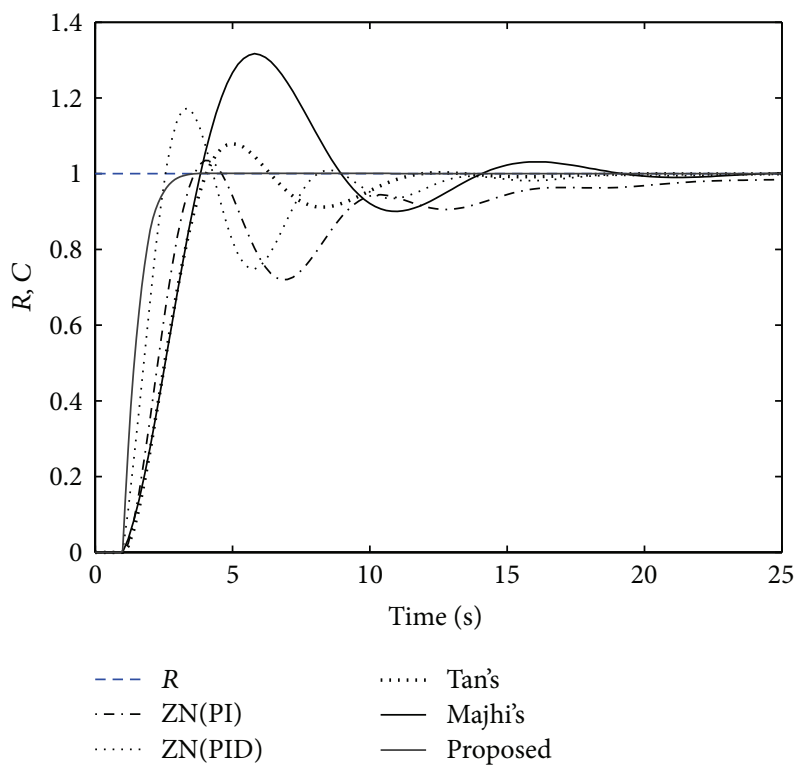

FIGURE 11: Comparisons with other methods for Example 1.

TABLE 2: The ISE and IAE of five methods for Example 1.

\begin{tabular}{lccccc}
\hline & Proposed & ZN(PI) & ZN(PID) & Tan's(PID) & Majhi's(PI) \\
\hline ISE & 1.347 & 2.268 & 1.770 & 2.247 & 2.465 \\
IAE & 1.599 & 4.011 & 2.876 & 3.073 & 4.066
\end{tabular}

Figure 12 shows time responses using optimization method and the proposed method for $R=1,5,10$, and 50. It can be seen that the proposed method gives better result than that of the optimization method.

Simulation results of the proposed method and four other methods are presented for comparisons also. They are rules of Ziegler-Nichols [18, 19] for finding PI and PID compensators, Ho et al. [22] for finding PID compensator, and Majhi 


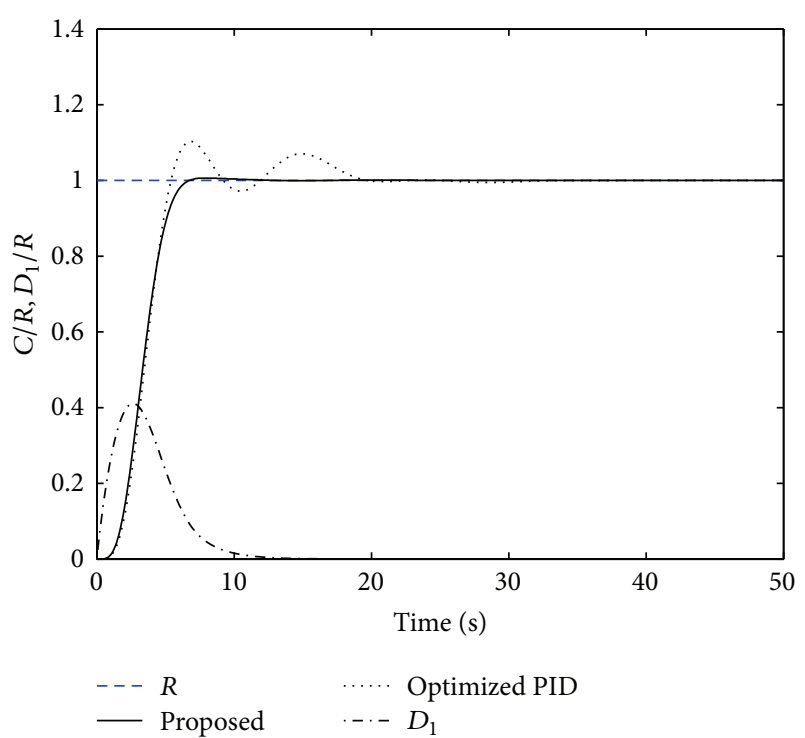

Figure 12: Normalized responses of $C / R$ and $D / R$ of Example 2.

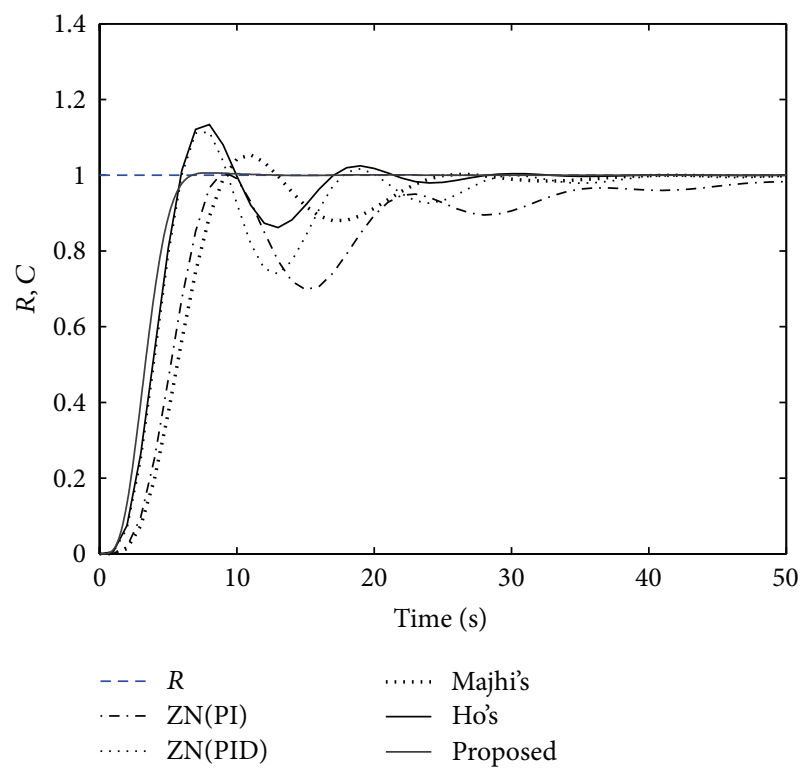

FIgURE 13: Comparisons with other methods for Example 2.

[17] for finding PI compensator. Parameters of five found compensators are given as follows.

(1) The proposed method:

$$
\begin{aligned}
& K_{p}=1.1800, \quad K_{i}=0.3380, \quad K_{d}=2.9181, \\
& K_{1}=0.0500, \quad K_{2}=1.5000, \quad K_{n}=0.5064, \quad \text { (18) } \\
& T_{n}=1.259 . \\
& \text { (2) } \mathrm{ZN}(\mathrm{PI}): K_{p}=1.079 \text { and } K_{i}=0.110 . \\
& \text { (3) } \mathrm{ZN}(\mathrm{PID}): K_{p}=1.4248, K_{i}=0.1838 \text {, and } K_{d}=1.360 . \\
& \text { (4) Majhi's(PI): } K_{p}=0.7736 \text { and } K_{i}=0.1547 . \\
& \text { (5) Ho's(PID): } K(s)=1.3(1+0.189 / s+1.3 s /(0.13 s+1)) .
\end{aligned}
$$

Time responses are shown in Figure 13. Integral of the square error (ISE) and integral of the absolute error (IAE) are given in Table 3. From Table 3 and Figure 13, one can see that the proposed method gives faster response and better performance than those of other methods.

Example 3. Consider the very high order plant [17]

$$
G(s)=\frac{1}{(s+1)^{20}} .
$$

Three parameters of the optimized PID controller are

$$
K_{p}=0.666, \quad K_{i}=0.06015, \quad K_{d}=4.4119 .
$$

The performance index 50IAE + ISE is used for finding them. The dominate pole for high gain $K_{2}=2.000$ is $+0.0089 \pm$ $j 0.1965\left(\omega_{n}=0.1967\right)$. Note that it is an unstable system. The low gain $K_{1}=0.200$ is selected. It is an overdamped system. Parameters found for the proposed control scheme are

$$
\begin{aligned}
K_{1}=0.20, \quad K_{2} & =2.000, \quad K_{n}=0.6851, \\
T_{n} & =5.0839 .
\end{aligned}
$$

Figure 14 shows time responses using optimization method and the proposed method for $R=1,5,10$, and 50. It can be seen that the proposed method gives better result than that of the optimization method. Note that the compensated system is a combination of an overdamped system and an unstable system. That is, the proposed control scheme can stabilize the system and gives fast response and good performance.

Simulation results of the proposed method and four other methods are presented for comparisons. They are methods of Ziegler-Nichols for finding PI and PID compensators [18, 19], Zhuang and Atherton [23] for finding PI compensator, and Majhi [17] for finding PI compensator. Parameters of five found compensators are given as follows.

(1) The proposed method:

$$
\begin{gathered}
K_{p}=0.666, \quad K_{i}=0.06015, \quad K_{d}=4.4119, \\
K_{1}=0.20, \quad K_{2}=2.000, \quad K_{n}=0.6851, \\
T_{n}=5.0839 .
\end{gathered}
$$

(2) $\mathrm{ZN}(\mathrm{PI}): K_{p}=0.585$ and $K_{i}=0.0305$.

(3) ZN(PID): $K_{p}=0.77256, K_{i}=0.05088$, and $K_{D}=$ 4.9135 .

(4) Zhuang's(PI): $K_{p}=0.473$ and $K_{i}=0.058$.

(5) Majhi's(PI): $K_{p}=0.5097$ and $K_{i}=0.0443$.

Integral of the square error (ISE) and integral of the absolute error (IAE) are given in Table 4. Time responses are shown in Figure 15. From Table 4 and Figure 15, one can see that the proposed method gives faster time responses and better performance than those of other mentioned methods. 


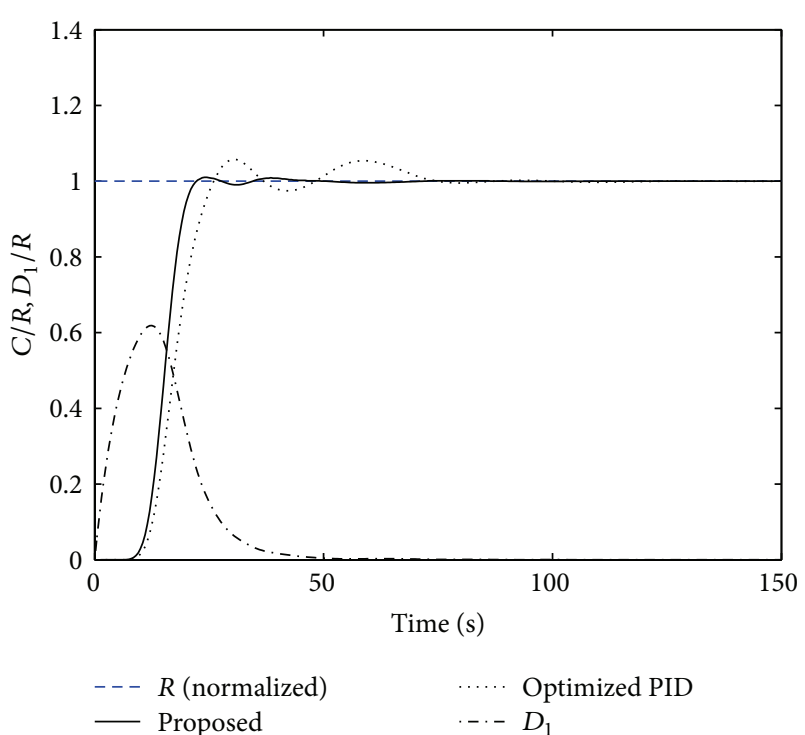

FIGURE 14: Normalized responses of $C / R$ and $D / R$ of Example 3.

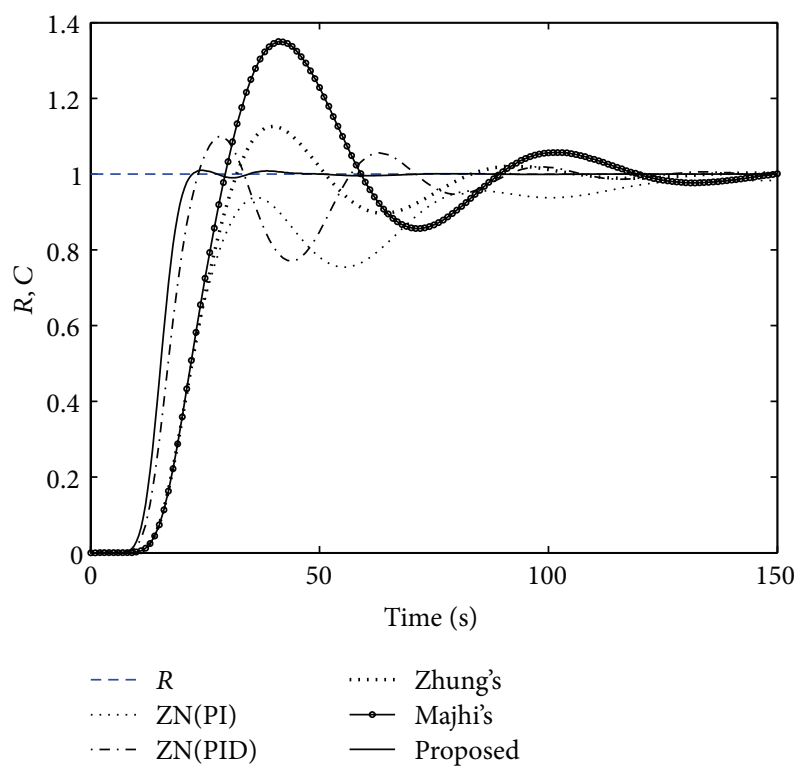

FIGURE 15: Comparisons with other methods for Example 3.

Example 4. Consider an electrohydraulic velocity/position servo control system [24] shown in Figure 16. The relation between the servo spool position $X_{v}$ and the input voltage $u$ is in the form of

$$
\frac{X_{v}}{u}=G_{v}(s)=\frac{K_{v}}{s^{2} / \omega_{v}^{2}+2 \xi_{v} s / \omega_{v}+1},
$$

where $K_{v}$ is the valve gain, $\xi_{v}$ is the damping ratio of the servo valve, and $\omega_{v}$ is the natural frequency of the servo valve. In general, (23) can be approximated by $X_{v}=K_{v} u$ for large $\omega_{v}$. The relation between the valve displacement $X_{V}$ and the load flow rate $Q_{L}$ is governed by the well-known orifice law [24]:

$$
Q_{L}=X_{V} K_{J} \sqrt{P_{S}-\operatorname{sign}\left(X_{V}\right) P_{L}}=X_{V} K_{s},
$$

TABLE 3: The ISE and IAE of five methods for Example 2.

\begin{tabular}{lccccc}
\hline & Proposed & ZN(PI) & ZN(PID) & Ho’s(PID) & Majhi’s(PI) \\
\hline ISE & 2.836 & 5.335 & 4.023 & 5.215 & 3.740 \\
IAE & 3.586 & 9.279 & 6.492 & 7.219 & 5.425 \\
\hline
\end{tabular}

TABLE 4: The ISE and IAE of five methods for Example 3.

\begin{tabular}{lccccc}
\hline & Proposed & ZN(PI) & ZN(PID) & Zhuang's(PID) & Majhi’s(PI) \\
\hline ISE & 14.108 & 21.227 & 16.216 & 20.191 & 21.814 \\
IAE & 16.164 & 32.708 & 22.971 & 26.830 & 32.913 \\
\hline
\end{tabular}

where $K_{j}$ is a constant for specific hydraulic motor; $P_{S}$ is the supply pressure; $P_{L}$ is the load pressure; and $K_{s}$ is the valve flow gain which varies at different operating points. The following continuity property of the servo valve and motor chamber yields

$$
Q_{L}=D_{m} \omega+C_{t p} P_{L}+\left(V_{t}-4 \beta_{o}\right) \dot{P}_{L}
$$

where $D_{m}$ is the volumetric displacement; $C_{t p}$ is the total leakage coefficient; $V_{t}$ is the total volume of the oil; $\beta_{o}$ is the bulk modulus of the oil; and $\omega$ is the velocity of the motor shaft. The torque balance equation for the motor is in the form of

$$
D_{m} P_{L}=J \dot{\omega}+B_{m} \dot{\omega}+T_{L}
$$

where $B_{m}$ is the viscous damping coefficient and $T_{L}$ is the external load disturbance which is assumed to be dependent upon the velocity of the shaft. The mathematical model of the considered system is shown in Figure 17. System parameters are given as follows:

$$
\begin{gathered}
K_{s}=2.3 \times 10^{-7} \sqrt{P_{S}-\operatorname{sign}\left(X_{V}\right) P_{L}} \mathrm{~m}^{2} / \mathrm{s}, \\
P_{S}=1.4 \times 10^{7} \mathrm{~N}_{\mathrm{t}} / \mathrm{m}^{2}, \quad K_{v}=0.5 \mathrm{~m} / \mathrm{v}, \\
\beta_{o}=3.5 \times 10^{7} \mathrm{~N}_{\mathrm{t}} / \mathrm{m}^{2}, \quad V_{t}=3.3 \times 10^{-5} \mathrm{~m}^{2} / \mathrm{rad}, \\
C_{t p}=2.3 \times 10^{-11} \mathrm{~m}^{5} / \mathrm{s} / \mathrm{N}_{\mathrm{t}}, \quad D_{m}=1.6 \times 10^{-5} \mathrm{~m}^{3} / \mathrm{rad}, \\
J=5.8 \times 10^{-3} \mathrm{Kg}-\mathrm{m}-\mathrm{s}^{2}, \quad B_{m}=0.864 \mathrm{Kg} \cdot \mathrm{m} \cdot \mathrm{s} / \mathrm{rad}, \\
\xi_{v}=0.4, \quad \omega_{v}=628 \mathrm{rad} / \mathrm{s} .
\end{gathered}
$$

The control configuration for velocity and position servo control of the considered system is shown in Figure 18, in which inner loop and outer loop adaptive nonlinear controllers are included.

Design results of the velocity control loop are discussed as follows.

(a) Inner Loop PI Controller. The PI controller is first found by the optimization toolbox of MATLAB for minimizing the integration of absolute errors (IAE), integration of square errors (ISE), and zero peak overshoot. Parameters of the PI controller are $K_{p}=1.127 \times 10^{-3}$ and $K_{i}=3.9632$. 


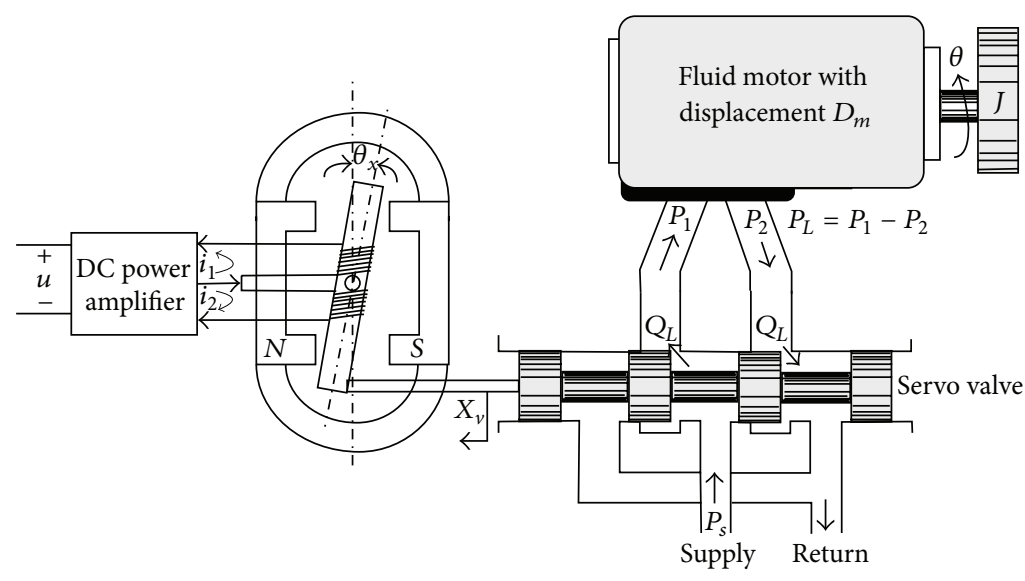

FIGURE 16: Block diagram of the electrohydraulic system.

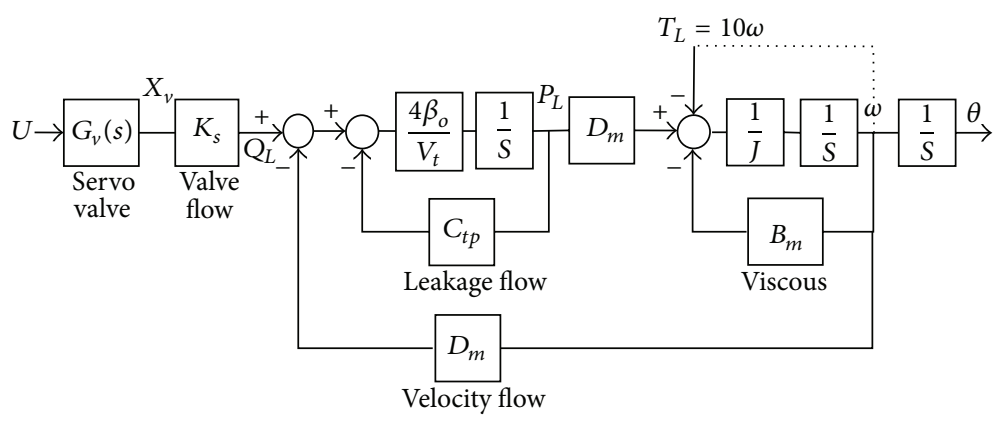

FIGURE 17: Mathematical model of the electrohydraulic system.

Time responses of the controlled system using the found PI controller are shown in Figure 19.

(b) Parameters of Inner Loop Adaptive Nonlinear Controller. Low gain $\left(K_{1}=1\right)$ and high gain $\left(K_{2}=9.223\right)$ are selected. The low gain case is the optimized result and the high gain case is the controlled system in the sustaining condition $\left(\omega_{n}=\right.$ $312.71 \mathrm{rad} / \mathrm{s})$. The $\omega_{n}=312.71 \mathrm{rad} / \mathrm{s}$ gives $T_{n}=0.003182$. $K_{n}=2.2889$ is found by (12) using Mps = 1.001. Time responses for low gain, high gain, and adaptive gain are shown in Figure 19. Rise times of the optimization method and the proposed method are $0.0202 \mathrm{sec}$ and $0.0124 \mathrm{sec}$, respectively. It shows that the proposed method can give faster response than that controlled by the optimized method. The gain/phase margins, phase/gain crossover frequencies, and rise times are given also in Table 5. It gives that controlled system using two methods has the same robustness while Figure 19 shows that the proposed method gives faster response.

Design results of the position control loop are discussed as follows.

(a) Outer Loop PI Controller. The PI controller is first found by the optimizations toolbox of MATLAB for minimizing the integration of absolute errors (IAE), integration of square errors (ISE), and zero peak overshoot. Parameters of the PI controller are $K_{p}=18.506$ and $K_{i}=0.3666$. Time responses of the controlled system using the found PI controller are shown in Figure 20.

(b) Parameters of Outer Adaptive Nonlinear Controller. Low gain $\left(K_{1}=1\right)$ and high gain $\left(K_{2}=7.877\right)$ are selected. The low gain case is the optimized result and the high gain case is the controlled system in the sustaining condition $\left(\omega_{n}=\right.$ $91.95 \mathrm{rad} / \mathrm{s})$. The $\omega_{n}=91.95 \mathrm{rad} / \mathrm{s}$ gives $T_{n}=0.0010875$. $K_{n}=13.5$ is found by (12) using Mps $=1.001$. Time responses for low gain, high gain, and adaptive gain are shown in Figure 20. Rise times of the optimization method and the proposed method are $0.0513 \mathrm{sec}$ and $0.0334 \mathrm{sec}$, respectively. It shows that the proposed method can give faster response than that controlled by the optimized method. Gain/phase margins, phase/gain crossover frequencies, and rise times are given also in Table 6. It gives that controlled system using two methods has same robustness while Figure 20 shows that the proposed method gives faster response.

\section{Conclusions}

The proposed adaptive piecewise linear controller has shown that controlled systems were reference input independent and both good performance and fast response were obtained simultaneously. Three-segment piecewise linear controller provided a switching algorithm for low gain and high systems, that is, low gain for performance and high gain for 


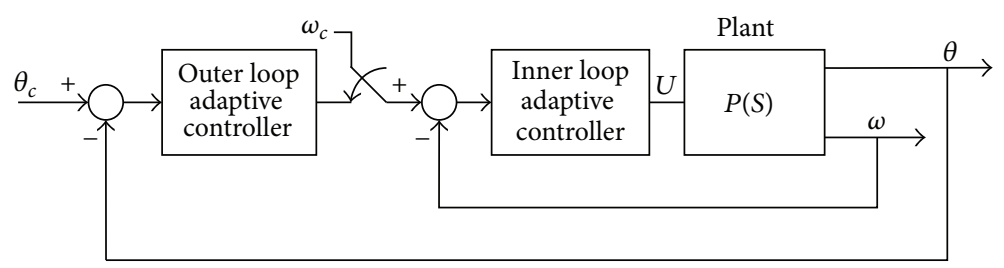

FIGURE 18: Control configuration of velocity and position servo control system.

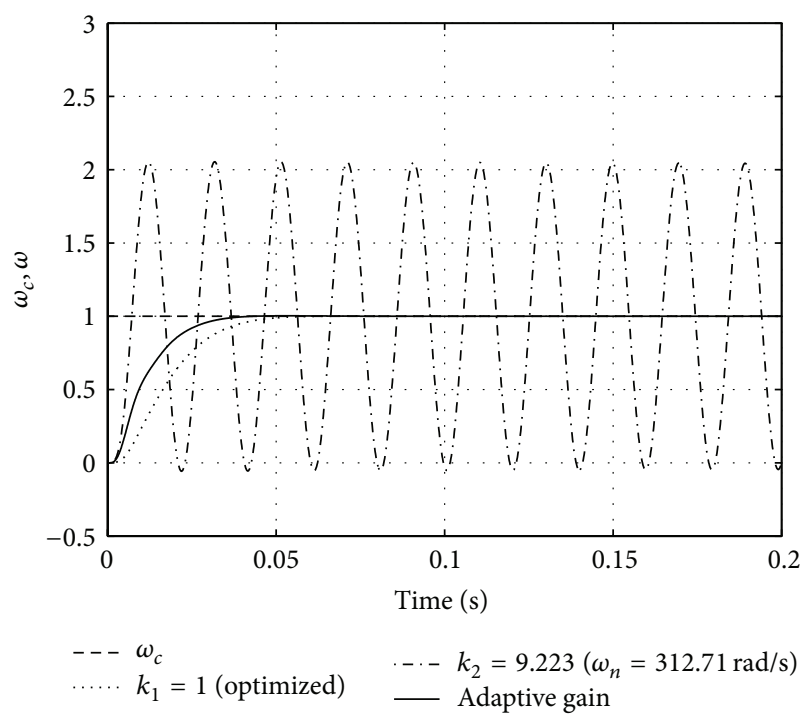

FIGURE 19: Time responses of velocity control system for low gain $\left(K_{1}=1\right)$ and high gain $\left(K_{2}=9.223\right)$ and adaptive gain.

TABLE 5: Gain/phase margins, phase/gain crossover frequencies, and rise times.

\begin{tabular}{lccccc}
\hline Method & $\mathrm{GM}$ & $\omega_{\mathrm{cp}}(\mathrm{Hz})$ & $\mathrm{PM}($ deg. $)$ & $\omega_{\mathrm{cg}}(\mathrm{Hz})$ & $\begin{array}{c}\text { Rise time } \\
(\mathrm{sec})\end{array}$ \\
\hline Optimization & 9.05 & 50.03 & 69.35 & 8.13 & 0.0202 \\
Adaptive gain & 9.19 & 49.73 & 69.35 & 8.13 & 0.0124 \\
\hline
\end{tabular}

TABLE 6: Gain/phase margins, phase/gain crossover frequencies, and rise times.

\begin{tabular}{lccccc}
\hline Method & $\mathrm{GM}$ & $\omega_{\mathrm{cp}}(\mathrm{Hz})$ & $\mathrm{PM}($ deg. $)$ & $\omega_{\mathrm{cg}}(\mathrm{Hz})$ & $\begin{array}{c}\text { Rise time } \\
(\mathrm{sec})\end{array}$ \\
\hline Optimization & 8.35 & 47.19 & 52.14 & 8.91 & 0.0513 \\
Adaptive gain & 8.39 & 47.22 & 51.09 & 8.71 & 0.0334 \\
\hline
\end{tabular}

response time. There are zero-damped, underdamped, and unstable systems used in Examples 1, 2, and 3 individually to get fast responses in large tracking phases.

Four numerical examples were designed and comparisons were made with six famous online computing and control methods. They have illustrated better performance and faster response provided by the proposed method than those of other mentioned methods.

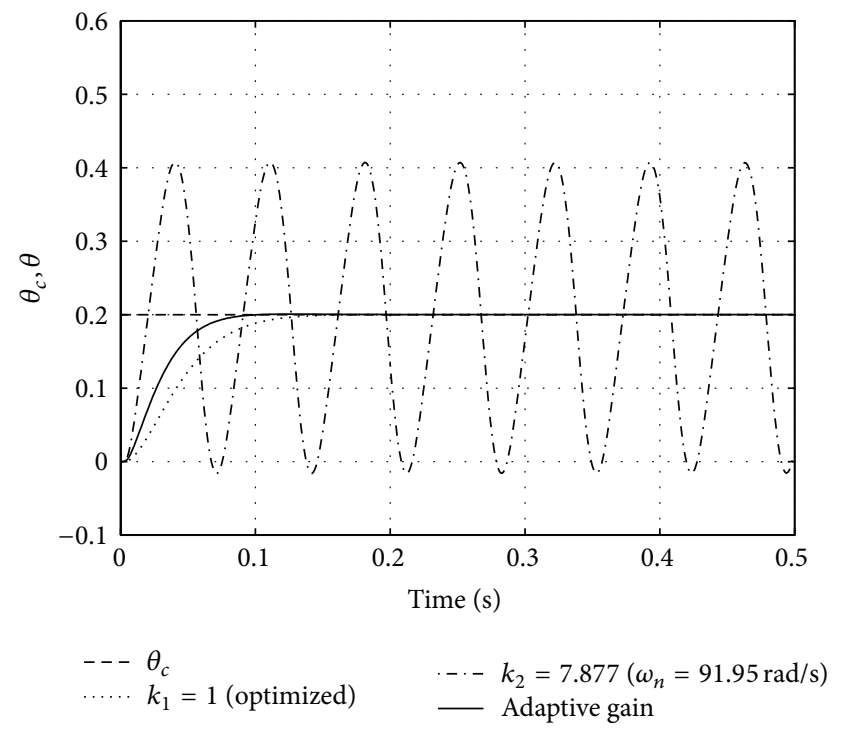

FIgURE 20: Time responses of position control system for $K_{1}=1$, $K_{2}=7.877$, and adaptive gain.

\section{Conflict of Interests}

The author declares that there is no conflict of interests regarding the publication of this paper.

\section{References}

[1] B. C. Kuo and F. Golnaraghi, Automatic Control Systems, John Wiley \& Sons, 8th edition, 2003.

[2] R. C. Dorf and R. H. Bisop, Modern Control Systems, Pearson Education, Singapore, 7th edition, 2008.

[3] V. I. Utkin, "Variable structure systems with sliding modes," IEEE Transactions on Automatic Control, vol. 22, no. 2, pp. 212222, 1977.

[4] G. Bartolini, E. Punta, and T. Zolezzi, "Simplex methods for nonlinear uncertain sliding-mode control," IEEE Transactions on Automatic Control, vol. 49, no. 6, pp. 922-933, 2004.

[5] J. Y. Hung, W. Gao, and J. C. Hung, "Variable structure control. A survey," IEEE Transactions on Industrial Electronics, vol. 40, no. 1, pp. 2-22, 1993.

[6] G. Bartolini, A. Ferrara, E. Usai, and V. I. Utkin, "On multiinput chattering-free second-order sliding mode control," IEEE Transactions on Automatic Control, vol. 45, no. 9, pp. 1711-1717, 2000. 
[7] S. R. Vadali, "Variable-structure control of spacecraft largeangle maneuvers," Journal of Guidance, Control, and Dynamics, vol. 9, no. 2, pp. 235-239, 1986.

[8] M. Corno, M. Tanelli, S. M. Savaresi, and L. Fabbri, "Design and validation of a gain-scheduled controller for the electronic throttle body in ride-by-wire racing motorcycles," IEEE Transactions on Control Systems Technology, vol. 19, no. 1, pp. 18-30, 2011.

[9] R. A. Nichols, R. T. Reichert, and W. J. Rugh, "Gain scheduling for H-infinity controllers: a flight control example," IEEE Transactions on Control Systems Technology, vol. 1, no. 2, pp. 69-78, 1993.

[10] T. A. Johansen, I. Petersen, J. Kalkkuhl, and J. Lüdemann, "Gainscheduled wheel slip control in automotive brake systems," IEEE Transactions on Control Systems Technology, vol. 11, no. 6, pp. 799-811, 2003.

[11] R. D. Colgren and E. A. Jonckheere, " $\mathrm{H}_{\infty}$ control of a class of nonlinear systems using describing functions and simplicial algorithms," IEEE Transactions on Automatic Control, vol. 42, no. 5, pp. 707-712, 1997.

[12] A. Nassirharand and H. Karimi, "Controller synthesis methodology for multivariable nonlinear systems with application to aerospace," Transactions of the ASME Journal of Dynamic Systems, Measurement and Control, vol. 126, no. 3, pp. 595-604, 2004.

[13] A. Nassirharand and H. Karimi, "Nonlinear controller synthesis based on inverse describing function technique in the MATLAB environment," Advances in Engineering Software, vol. 37, no. 6, pp. 370-374, 2006.

[14] T.-S. Tsay, "Automatic regulation time series for industry processes," Mathematical Problems in Engineering, vol. 2012, Article ID 710690, 16 pages, 2012.

[15] W. K. Ho, T. H. Lee, H. P. Han, and Y. Hong, "Self-tuning IMCPID control with interval gain and phase margins assignment," IEEE Transactions on Control Systems Technology, vol. 9, no. 3, pp. 535-541, 2001.

[16] T.-S. Tsay, "On-line computing of PI/lead compensators for industry processes with gain and phase specifications," Computers and Chemical Engineering, vol. 33, no. 9, pp. 1468-1474, 2009.

[17] S. Majhi, "On-line PI control of stable processes," Journal of Process Control, vol. 15, no. 8, pp. 859-867, 2005.

[18] J. G. Ziegler and N. B. Nichols, "Optimum setting for automatic controller," Transactions of the ASME, vol. 65, pp. 759-768, 1942.

[19] K. J. Åström and T. Hägglund, "Revisiting the Ziegler-Nichols step response method for PID control," Journal of Process Control, vol. 14, no. 6, pp. 635-650, 2004.

[20] K. K. Tan, T. H. Lee, and X. Jiang, "Robust on-line relay automatic tuning of PID control systems," ISA Transactions, vol. 39, no. 2, pp. 219-232, 2000.

[21] K. K. Tan, T. H. Lee, and X. Jiang, "On-line relay identification, assessment and tuning of PID controller," Journal of Process Control, vol. 11, no. 5, pp. 483-496, 2001.

[22] W. K. Ho, C. C. Hang, and L. S. Cao, "Tuning of PID controllers based on gain and phase margin specifications," Automatica, vol. 31, no. 3, pp. 497-502, 1995.

[23] M. Zhuang and D. P. Atherton, "Automatic tuning of optimum PID controllers," IEE Proceedings D: Control Theory and Applications, vol. 140, no. 3, pp. 216-224, 1993.

[24] H. E. Merritt, Hydraulic Control System, John Wiley \& Sons, New York, NY, USA, 1967. 


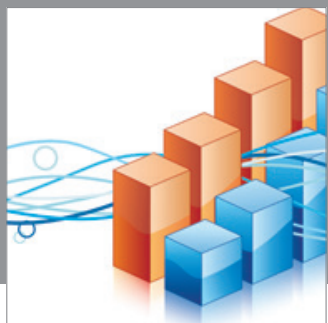

Advances in

Operations Research

mansans

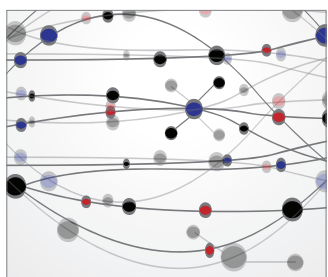

The Scientific World Journal
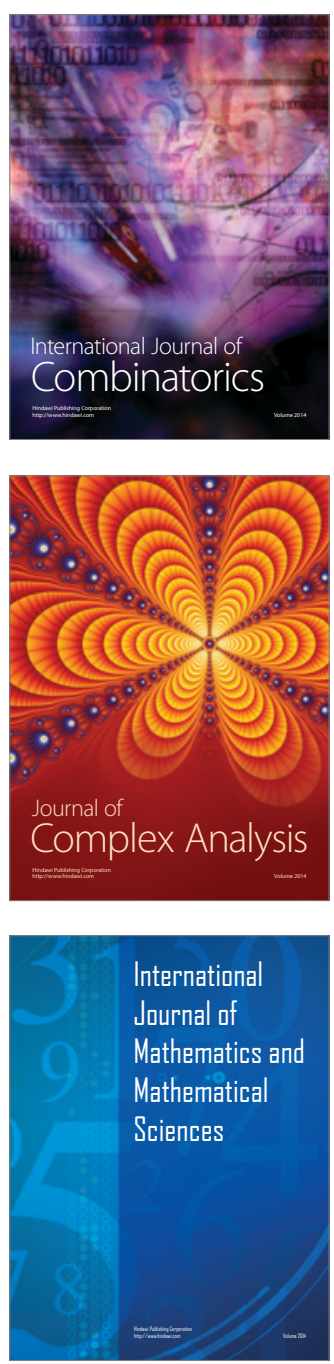
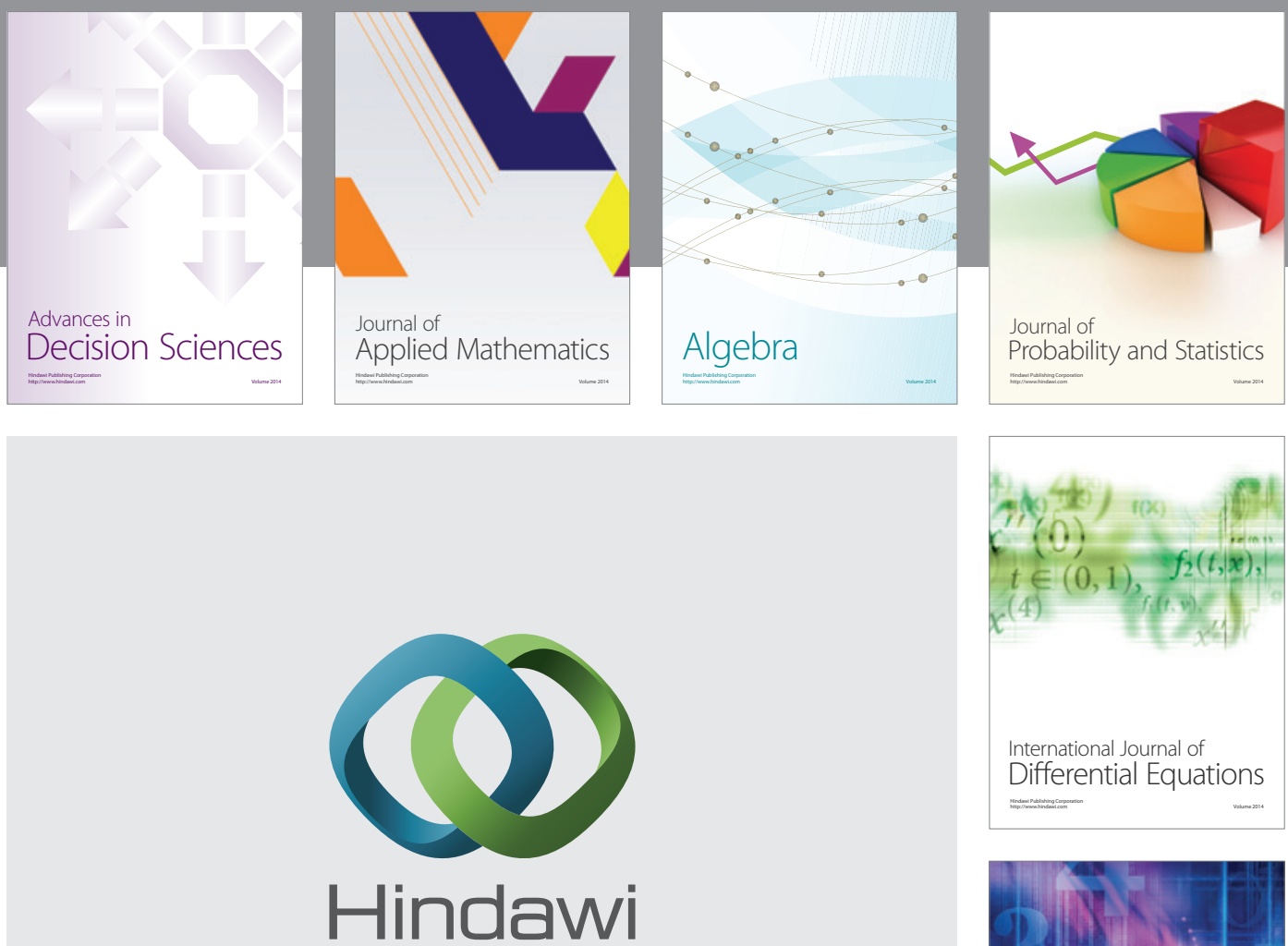

Submit your manuscripts at http://www.hindawi.com
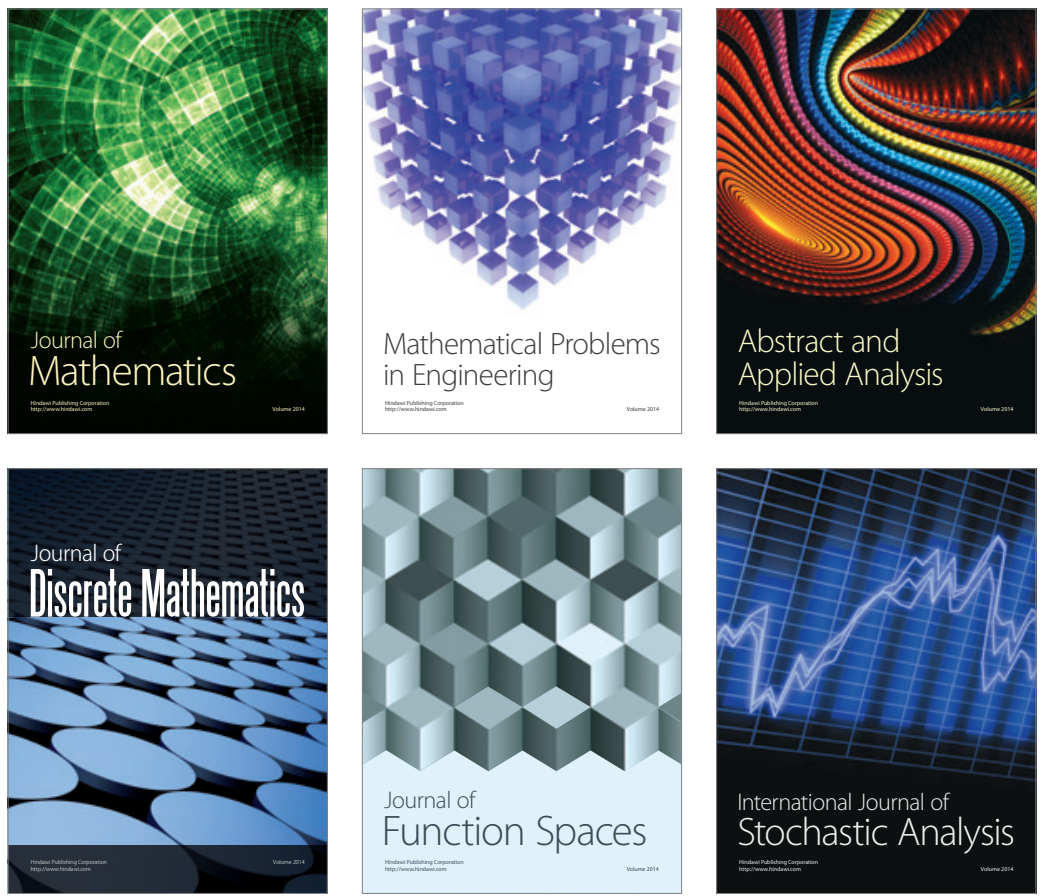

Journal of

Function Spaces

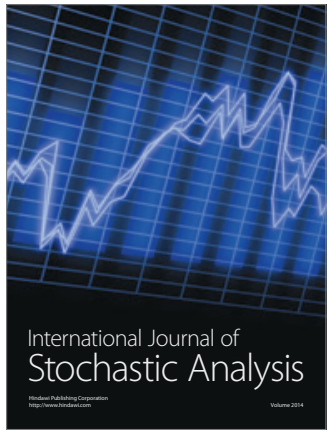

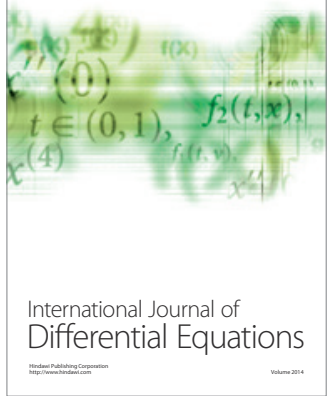
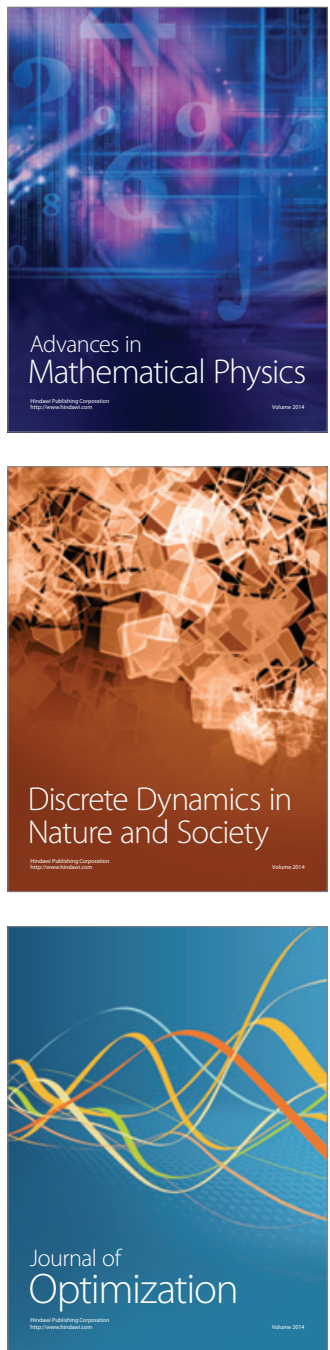